OPEN ACCESS

Edited by: Elena Ratner,

Yale University, United States

Reviewed by: Pietro Valerio Foti, Università degli Studi di Catania, Italy Connie Irene Diakos, University of Sydney, Australia

${ }^{*}$ Correspondence:

Charles A. Kunos charles.kunos@nih.gov

Specialty section: This article was submitted to Women's Cancer, a section of the journal Frontiers in Oncology

Received: 27 February 2018 Accepted: 23 April 2018 Published: 07 May 2018

Citation: Kunos CA and Ivy SP (2018) Triapine Radiochemotherapy in Advanced Stage Cervical Cancer.

Front. Oncol. 8:149. doi: 10.3389/fonc.2018.00149

\section{Triapine Radiochemotherapy in Advanced Stage Cervical Cancer}

\author{
Charles A. Kunos* and S. Percy Ivy \\ Cancer Therapy Evaluation Program, National Cancer Institute, Bethesda, MD, United States
}

Clinical ribonucleotide reductase (RNR) inhibitors have reinvigorated enthusiasm for radiochemotherapy treatment of patients with regionally advanced stage cervical cancers. About two-thirds of patients outlive their cervical cancer (1), even though up to half of their tumors retain residual microscopic disease (2). The National Cancer Institute Cancer Therapy Evaluation Program conducted two prospective trials of triapinecisplatin-radiation to improve upon this finding by precisely targeting cervical cancer's overactive RNR. Triapine's potent inactivation of RNR arrests cells at the G1/S cell cycle restriction checkpoint and enhances cisplatin-radiation cytotoxicity. In this article, we provide perspective on challenges encountered in and future potential of clinical development of a triapine-cisplatin-radiation combination for patients with regionally advanced cervical cancer. New trial results and review presented here suggest that a triapine-cisplatin-radiation combination may offer molecular cell cycle target control to maximize damage in cancers and to minimize injury to normal cells. A randomized trial now accrues patients with regionally advanced stage cervical cancer to evaluate triapine's contribution to clinical benefit after cisplatin-radiation (clinicaltrials.gov, NCT02466971).

Keywords: triapine, cervical cancer, uterine cervix cancer, vaginal cancer, radiation therapy, cisplatin

\section{INTRODUCTION}

Cervical cancer forecasts as the fourth most common any-type cancer in women worldwide in 2018 (3). And it remains the fourth leading cause of cancer-related death (3). About $36 \%$ of new cases in American women are staged as regionally advanced at first diagnosis (4). This means that their disease is confined in the cervix or nearby organs or lymph nodes (International Federation of Gynecology and Obstetrics stage IB2 to IVA). Patients with this stage of disease undergo once weekly cisplatin chemotherapy $\left(40 \mathrm{mg} \mathrm{m}^{-2}\right)$ and daily radiation (180 cGy per Monday to Friday) repeated for 5 weeks followed by intracavitary brachytherapy $(1,5)$. A 60 -month $(5$-year) survival rate for such treated patients is $60 \%$ (1).

Prognostic factors such as cell type, histological grade, and invasiveness provide only a partial explanation of why only 6 in 10 survive after cisplatin-radiation (6). An overactive DNA damage response that involves ribonucleotide reductase (RNR) might further explain this clinical result $(7,8)$. RNR substitutes a hydroxyl group in a ribonucleotide diphosphate for hydrogen for its corresponding deoxyribonucleoside diphosphate (dNDP) that ultimately can be used in DNA duplication or its repair (9). Both of its higher order $\left(\alpha_{6} \beta_{6}\right.$ or $\left.\alpha_{6} \beta_{2}\right)$ forms are active (10). RNR's large subunit $\alpha$ (M1) contains: (1) a catalytic pocket for rNDP substrates; (2) a specificity site that controls which nucleotides are made; and (3) an activity site that regulates its own activity through biologic feedback (11). Its catalytic pocket is the drug target for gemcitabine (12). RNR's small subunit $\beta$ (M2 or M2b) shuttles a critical diferric tyrosyl radical to the M1 subunit's catalytic site (13). The free radical is the drug target for hydroxyurea or triapine $(14,15)$. The response to DNA damage will be different 
depending on cell cycle status (Figure 1). M1 is long-lived and found in all cell cycle phases (16). M2 has a KEN-box sequence recognized by the Cdh1-anaphase-promoting complex that degrades it in late mitosis $(17,18)$. M2b lacks the KEN-box and thus can be detected in all cell cycle phases. M2b transcription is p53 dependent (19). This means that cancers in G1-phase of the cell cycle do not have M2 available to pair up with M1 for active enzyme, and therefore, must depend upon M2b to be available for active enzyme. When a drug like triapine inactivates RNR, deoxynucleoside salvage kinases supply DNA precursors for duplication or repair (20).

Triapine (3-aminopyridine-2-carboxaldehyde thiosemicarbazone) potently blocks RNR activity (15). But triapine as monotherapy has been ineffective $(0-7 \%$ response rate) in the clinic when given up to $96 \mathrm{mg} \mathrm{m}^{-2}$ daily (23-25). A triapinecisplatin combination was tolerable but also clinically ineffective with no observed responses (26). A triapine-cisplatin-paclitaxel combination too was tolerable but found to not result in objective responses (27). Cancer Therapy Evaluation Program (CTEP) repositioned triapine as a radiation modifier in 2006. Early experiments showed that confluent and growth-arrested cervical cancer cells had a 17-fold rise in RNR M2 expression about $18 \mathrm{~h}$ after radiation exposure (28). There was also a fourfold increase in their RNR dNDP output (or DNA precursor output) about $24 \mathrm{~h}$ after radiation exposure (28). Later experiments reinforced the notion that triapine offers molecular target control of RNR activity for up to $18 \mathrm{~h}$ until M2 expression restores enzyme output (29). It was shown that triapine strongly arrested cells at a G1/S-phase cell cycle restriction checkpoint for up to $18 \mathrm{~h}$, left radiation-induced DNA damage unrepaired for at least $6 \mathrm{~h}$, and profoundly sensitized cancers to radiation-cisplatin cytotoxicity (20-22, 30).

This article provides a state-of-the-art perspective on a triapinecisplatin-radiation combination for the treatment of regionally advanced stage cervical cancer. The first trial (\#7336) reviewed here was a phase I dose-finding safety study (clinicaltrials.gov,

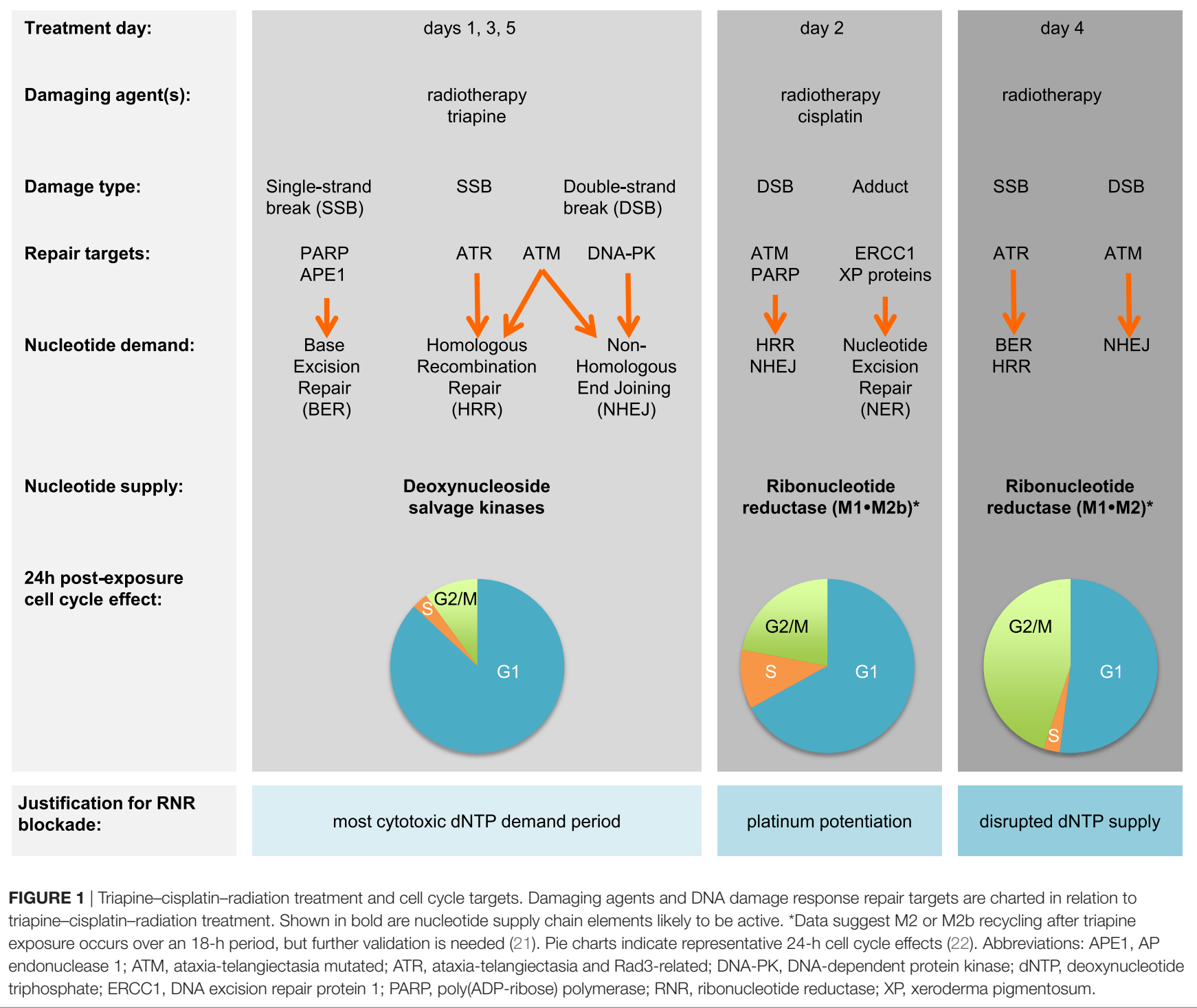


NCT00335998) (31). The second trial (\#8327) was a single-arm phase II efficacy study (clinicaltrials.gov, NCT00941070) (32). Now that the median survivor follow-up in the two trials exceeds 6 years, CTEP offers perspective on the challenges encountered and opportunities gained for clinical development of triapine as an anticancer agent.

\section{CHALLENGES AND OPPORTUNITIES}

Cancer Therapy Evaluation Program's studies activated as a phase I trial in 2006 (\#7336) and then a phase II trial in 2009 (\#8327). The first trial recruited patients mainly with cervical cancers of any stage [10 (91\%) of 11] (31). The second trial accrued any stage cervical or vaginal cancers (32). Tumor stage heterogeneity has posed a challenge to long-term interpretation of front-line triapine impact upon established cisplatin-radiation combination treatment. First, in CTEP trials, any cervical cancer disease lying outside a pelvic radiotherapy treatment beam portal was not irradiated, negating any possibility of radiation-triapine synergistic cytotoxicity. This too means that those front-line patients with initial extrapelvic or metastatic disease only had their unirradiated disease treated by cisplatin-triapine, which may have only modest anticancer activity in cervical cancer patients (26). In this article, we assessed long-term patient outcomes from those patients with only regionally advanced stage cervical (IB2 to IVA) or vaginal (II to IVA) cancers recruited in its trials. Patients previously analyzed were excluded for this article if they had metastatic disease at treatment onset $(n=4)$, extrapelvic disease $(n=2)$, death due to protocol-unrelated iatrogenic Mallory-Weiss tear $(n=1)$, or if they consented but had no treatment $(n=1)$. Twenty-nine patients are thus discussed below.

Another challenge in front-line triapine clinical development has been its administration schedule (Table 1). In trials, radiotherapy involved 25-fraction (180 cGy) Monday through Friday four-field box radiation beginning on day 1 . This was followed by low-dose-rate (LDR) brachytherapy in one or two implants (day 49 or $56 \pm 3$ days). Or, there was an option for high-dose-rate (HDR) brachytherapy in five implants (e.g., days 42, 45, 49, 52, and 56). Total treatment time was to be $56 \pm 3$ days. The total prescription was 8,000 cGy (LDR) or 7,500 cGy (HDR) or more as clinically indicated. Cisplatin $\left(40 \mathrm{mg} \mathrm{m}^{-2}\right.$ capped at $70 \mathrm{mg}$ ) was moved to a Tuesday intravenous infusion (day 2). There was a treating physician's option for a sixth infusion on day $36 \pm 3$ days. Because of triapine's 2 -h half-life, triapine $(25 \mathrm{mg}$ $\mathrm{m}^{-2}$ ) intravenous infusions were scheduled three times per week beginning on day 1 . An often-held perception is that the number of triapine infusions is cumbersome to patients. To correct this notion, there may be an opportunity to study the oral triapine formulation (33) in this patient population as proposed in CTEP protocol \#9892.
From the CTEP perspective, its trials were the first to used ${ }^{18} \mathrm{~F}$-fluorodeoxyglucose (FDG) positron emission tomography (PET) at baseline and 3 months after treatment completion for prognostic treatment response assessment. This third challenge necessitated evaluation of its FDG PET metabolic response criteria, as there is the possibility of overestimating metabolic complete or partial response due to a substantial radiation cytotoxicity effect. In the trials, cervical tumor and lymph node regions defined on baseline scan were drawn as regions of interest (ROI) that would then be assessed on a 3-month follow-up scan. Uptake measurements were made for mean and maximum tumor ROI counts per pixel per second (calibrated as $\mathrm{MBq} \mathrm{L}^{-1}$ ). The original FDG PET metabolic response evaluation criteria are found elsewhere (34). Briefly, a metabolic complete response was defined as absence of abnormal FDG uptake at sites of abnormal FDG uptake noted on the baseline scan. Partial metabolic response was $15-25 \%$ reduction in tumor FDG uptake. Stable metabolic response ranged between less than $15 \%$ reduction or less than or equal to $25 \%$ gain in tumor FDG uptake. Progressive metabolic disease was labeled as greater than $25 \%$ gain in tumor FDG uptake or appearance of new FDG uptake in metastatic lesions. On CTEP's trials in cervical cancer, a computed tomography scan was co-acquired for anatomic detail. To overcome challenges, there was an opportunity to apply a vetted ratio of 3-month post-treatment to baseline pretreatment FDG uptake in cervical tumor. A benchmark threshold ratio of 0.33 was applied for $\mathrm{mCR}$ (35). In these two trials, the 0.33 ratio benchmark served well as prognostic indicator of best response. There is further possibility to evaluate the performance of the 0.33 ratio benchmark in CTEP's current randomized trial (clinicaltrials.gov, NCT02466971).

\section{PERSPECTIVES ON NEW TRIAL FINDINGS}

Original patient demographics and tumor characteristics are summarized elsewhere $(31,32)$. The median age of the combined patients in this 29-patient analysis was 57 years, ranging between 33 and 68 years. All patients were female. Self-identified race was white $(72 \%)$ or American black (28\%). Ten percent identified their ethnicity as Hispanic or Latino. Squamous cell carcinoma was the most common type of tumor histopathology (93\%). The 29-patient data in this analysis have a cutoff date of October 24, 2017.

Triapine-cisplatin-radiation appears safe and tolerable. Updated results for adverse events on these trials reveal immediate grade 3 or 4 gastrointestinal (nausea $11 \%$, diarrhea $8 \%$, anorexia $3 \%$, and dehydration $3 \%$ ) or hematological toxicities (thrombocytopenia 20\%, lymphocyte decrease 16\%, and anemia $7 \%$ ) to be generally mild, reversible, but attributable to the combination. Triapine has one adverse event of particular interest to CTEP and requires adverse event of special interest

TABLE 1 | Triapine-cisplatin-radiation weekly ${ }^{a}$ treatment schedule.

\begin{tabular}{|c|c|c|c|c|c|c|}
\hline Monday & Tuesday & Wednesday & Thursday & Friday & Saturday & Sunday \\
\hline Triapine & Cisplatin & Triapine & - & Triapine & - & - \\
\hline Pelvic radiation & Pelvic radiation & Pelvic radiation & Pelvic radiation & Pelvic radiation & - & - \\
\hline
\end{tabular}

aTreatment began on Monday day 1, and repeated each week for a total of 5 weeks (i.e., days 1, 8, 15, 22, and 29). 
reporting-methemoglobinemia. Triapine interacts with $\mathrm{Fe}(2+)$ hemoglobin forming $\mathrm{Fe}(3+)$ methemoglobin that does not deliver oxygen. For context, $\mathrm{Fe}(2+)$ hemoglobin normally auto-oxidizes to inactive $\mathrm{Fe}(3+)$ methemoglobin at a rate of nearly $3 \%$ per day. A reductase system counterbalances this process to normally limits methemoglobin concentrations to less than $1 \%$. Given repeated exposure to triapine during the course of cisplatin-radiation treatment in these trials, methemoglobinemia and symptoms of dyspnea were monitored by CTEP on both trials. Management guidelines for methemoglobinemia were included in each protocol and can be reviewed elsewhere (36). At a recommended phase II trial dose of triapine $25 \mathrm{mg} \mathrm{m}^{-2}$, methemoglobinemia peaked on average at $2 \%$. As compared to pre-infusion baseline, this post-infusion proportion was on average a fivefold rise in methemoglobin. The trials collectively observed one (3\%) rectovaginal fistula occurring 22 months after treatment. This patient underwent diverting colostomy and hyperbaric oxygen treatment to aid healing of the rectovaginal fistula. Late ureteral obstruction was not encountered. An increased emphasis on morbidity outcomes as a component of regulatory filing makes careful monitoring of adverse events critical on the randomized trial of the triapine-cisplatin-radiation combination.

Confirmed clinical complete responses after triapine-cisplatinradiation treatment were $100 \%$ on these trials (29 of 29 , Table 2). Confirmed mCR rate was $95 \%$ (21 of 22, Table 2). Median FDG PET uptake before treatment was 14.3 (range 6.9-32.1) in the 29 patients analyzed here. Median uptake after triapine-cisplatin-radiation treatment was 2.8 (range 1.1-6.4) for the same population. A median uptake ratio was, therefore, resulted at 0.19 (range 0.06-0.56). A single patient who did not achieve an uptake ratio of less than 0.33 had the only partial metabolic response after combination treatment. And this patient developed progressive disease in an intrapelvic lymph node 8 months after combination treatment.

For this article, an overall survival analysis was based on a total of 15 deaths from among the 29 eligible patients with regionally advanced stage cervical or vaginal cancer. The median follow-up from date of first treatment to database lock, censoring observed deaths, was 73 months (range, 58-129 months). A total of 25 $(86 \%)$ of 29 patients survived either disease-free $(n=14)$ or died from a variety of non-cancer causes $(n=11)$. The low number of deaths on these two trials means that overall survival estimates are underpowered to show meaningful differences between triapine-cisplatin-radiation and historical cisplatin-radiation controls. Thus, the data here should be treated as preliminary. Overall survival estimates after triapine-cisplatin-radiation treatment was $83 \%(95 \% \mathrm{CI}, 63-92 \%)$ at 30 months and $59 \%$ (95\% CI, 39-74\%) at 60 months (5 years). These two times were arbitrarily selected to match reporting in long-term analyses of cisplatin-radiation phase III trials in a similarly recruited cervical cancer patient population. In the comparator, estimates for overall survival after cisplatin-radiation treatment were $70 \%$ for 30 months and $60 \%$ for 60 months (5 years) (1). In an interesting subset of the 29-patient cohort analyzed here, 15 (52\% of 29 ) patients at diagnosis had FDG PET-avid pelvic lymph nodes. Their overall survival after triapine-cisplatin-radiation combination treatment was $80 \%(95 \% \mathrm{CI}, 50-93 \%)$ at 30 months and $60 \%$ (95\% CI, 32-80\%) at 48 months (4 years). In another study, estimated overall survival after cisplatin-radiation treatment in patients with FDG PET-avid pelvic lymph nodes was $50 \%$ at 30 months and $45 \%$ at 48 months (4 years) (41). CTEP regards this latter finding quite remarkable.

\section{POTENTIAL FOR TRIAPINE IN CERVICAL CANCER}

In these two trials, triapine-cisplatin-radiation was a safe therapeutic investigational option for patients with untreated regionally advanced stage cervical or vaginal cancers. Patients had improvement in pelvic disease response and overall survival, suggesting pelvic disease control lowered the risk of cancerrelated death.

Immediate adverse events related to triapine-cisplatinradiation were mild and manageable in both trials. The trials did

TABLE 2 | Responses ${ }^{\text {a }}$ of cervical tumor to indicated treatment.

\begin{tabular}{|c|c|c|c|c|}
\hline & Triapine-cisplatin-radiation & Cisplatin-radiation & Cisplatin-alone & Radiation-alone \\
\hline Cisplatin dose (frequency) & $40 \mathrm{mg} \mathrm{m}^{-2}$ (x1 weekly) & $30 \mathrm{mg} \mathrm{m}^{-2}$ (x1 weekly) & $50 \mathrm{mg} \mathrm{m}^{-2}$ (q3 weeks) & Placebo \\
\hline Evaluable & 29 & 50 & 150 & 43 \\
\hline Clinical complete response (CR) & $29(100 \%)$ & $44(88 \%)$ & $15(10 \%)$ & $21(49)$ \\
\hline Clinical partial response (PR) & $0(0 \%)$ & $6(12 \%)$ & $16(11 \%)$ & $7(16 \%)$ \\
\hline Clinical stable disease & $0(0 \%)$ & $0(0 \%)$ & $60(40 \%)$ & $7(16 \%)$ \\
\hline Clinical progressive disease & $0(0 \%)$ & $0(0 \%)$ & 59 (39\%) & $8(19 \%)$ \\
\hline All clinical responses (CR + PR) & 24 (100\%) & 50 (100\%) & $31(21 \%)$ & $28(65 \%)$ \\
\hline Reference & $(31,32)$ & $(37)$ & (38) & (39) \\
\hline Cisplatin dose (frequency) & $40 \mathrm{mg} \mathrm{m}^{-2}$ (x1 weekly) & $40 \mathrm{mg} \mathrm{m}^{-2}$ (x1 weekly) & & \\
\hline Evaluable & 22 & 238 & & \\
\hline Metabolic complete response (mCR) & $21(95 \%)$ & $173(73 \%)$ & & \\
\hline Metabolic partial response (mPR) & $1(4 \%)$ & 40 (17\%) & & \\
\hline Metabolic stable disease & $0(0 \%)$ & $0(0 \%)$ & & \\
\hline Metabolic progressive disease & $0(0 \%)$ & $25(10 \%)$ & & \\
\hline All metabolic responses (mCR + mPR) & 22 (100\%) & $213(89 \%)$ & & \\
\hline Reference & $(31,32)$ & (40) & & \\
\hline
\end{tabular}

FDG PET, ${ }^{18}$ F-fluorodeoxyglucose positron emission tomography.

${ }^{a}$ Response Evaluation Criteria in Solid Tumors, version 1.0. 
find an elevated rate of grade 3 or 4 platelet count decrease (20\%). Cisplatin causes platelet apoptosis (42), possibly mediated by mitochondrial DNA depletion and apoptosis (43). Triapine could possibly exacerbate this effect. In a previous cisplatin-radiation trial, grade 3 or 4 platelet count decreases were seen in $1 \%$ of patients (44). The observed $16 \%$ rate of grade 3 or 4 leukopenia in these trials was similar to a $13 \%$ rate seen elsewhere (44). Rare late gastrointestinal or urological adverse events here were similar to prior trials. The limited adverse event profile demonstrated in these two trials suggests that there is further potential for combination clinical development.

Estimated survival was $83 \%$ at 30 months after triapinecisplatin-radiation as upfront treatment for patients with regionally advanced stage cervical or vaginal cancer. This is better than the $70 \%$ rate at 30 months after cisplatin-radiation alone (1). But here patient survival must be interpreted cautiously, as sample sizes, and numbers of death events are both low in these two trials. It is known that up to half of primary cervix tumors retain residual microscopic cancer (2). This fits with an early cancer disease relapse pattern, as about $80 \%$ of disease relapses occur within 24 months after radiotherapy completion (1). In these two trials, triapine-cisplatin-radiation provided near total clinical and mCR (95\%) in cervical or vaginal tumors. Many survived disease-free or died from other causes than cancer. In the absence of thorough microscopic examination after radical adjuvant surgery, it is impossible to determine triapine's contribution to complete sterilization of residual microscopic disease. Here, FDG PET signal might serve as an unproven surrogate. A randomized trial better designed to test triapine's contribution to clinical benefit is now active (clinicaltrials.gov, NCT02466971).

Two cell cycle concepts lie behind potential strategies targeting cancer DNA damage responses mediated at least in part by RNR activity (Figure 2). As outlined elsewhere (45), triapine increases susceptibility of cancers to G1-phase or S-phase-induced DNA damage. If the levels of G1-phase damage are sufficient, this can lead to cell death through replication

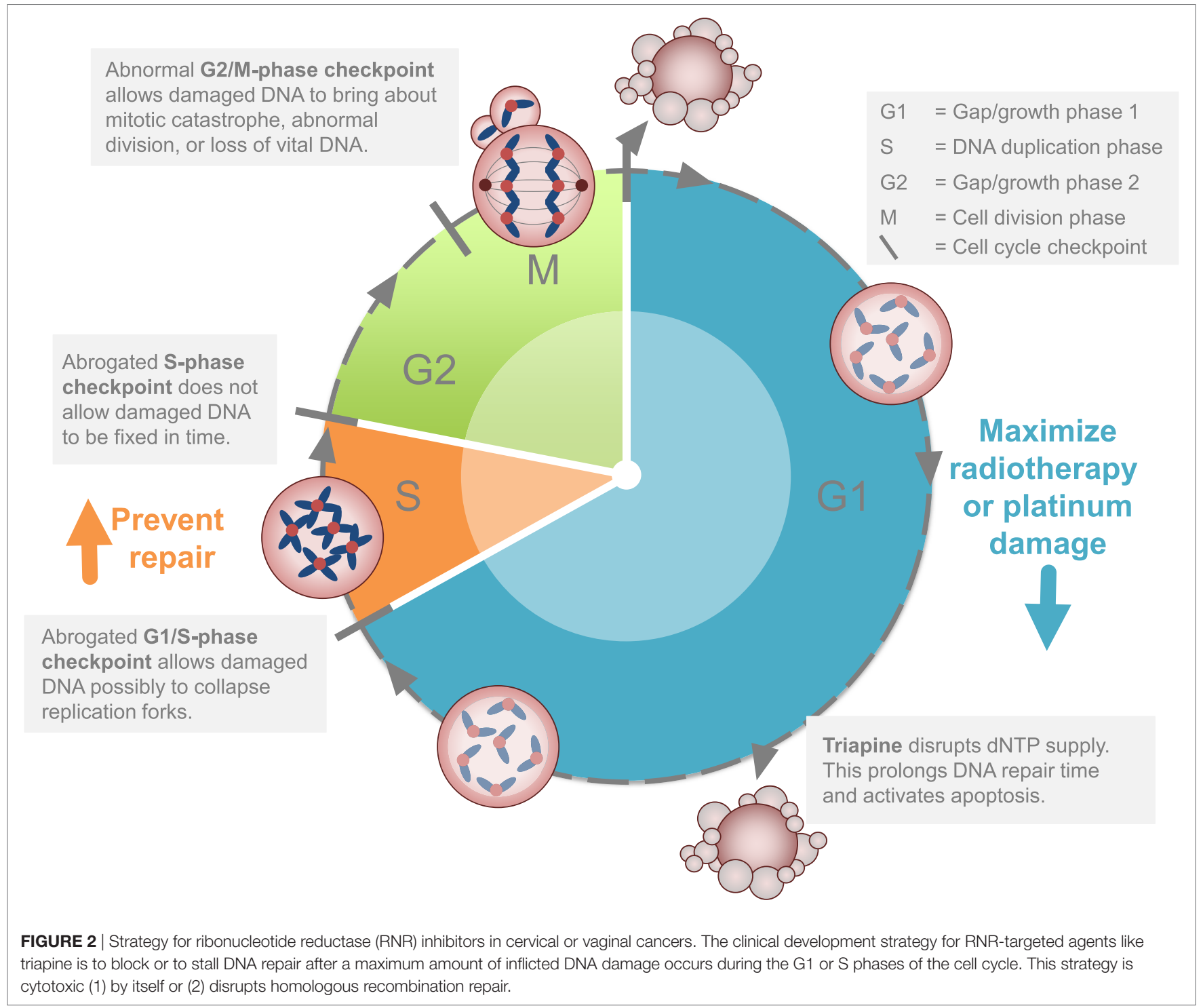


catastrophe (46) or apoptosis (47). Cancer cell death may also happen if double-strand DNA damage carries through into mitosis, resulting in mitotic catastrophe (45). This would explain why radiation, which exerts its cytotoxic effect most powerfully in either the G1-phase or the G2-M-phase, pairs well with cisplatin, which manifests S-phase DNA damage. This would also explain why triapine might be so effective in combination with radiation-cisplatin. Sustained radiation-cisplatin DNA damage demands nucleotides for repair. Biologic agents like triapine render RNR small $\beta$ subunits inactive and therefore places a much greater dependency on alternative nucleotide sources like deoxynucleoside salvage kinases. Sufficient DNA damage may be generated to exceed the threshold where cancer cells survive on alternative nucleotide sources, regardless of intact or exhausted cell cycle restriction checkpoints. RNR inhibitors that can maximize DNA damage, such as gemcitabine or hydroxyurea or triapine, provide means to overcome nucleotide supply as a vital cancer defense mechanism. In the two trials discussed here, evidence of improved disease response and patient survival advocate for this strategic attack on the cancer cell cycle.

In summary, these two trials provide response and survival evidence that triapine-cisplatin-radiation is effective in patients with regionally advanced stage cervical or vaginal cancer. Future studies should consider oral triapine for RNR blockade for patients in first-line cisplatin-radiation treatment.

\section{REFERENCES}

1. Rose P, Ali S, Watkins E, Thigpen J, Deppe G, Clark-Pearson D, et al. Long-term follow-up of a randomized trial comparing concurrent single agent cisplatin, cisplatin-based combination chemotherapy, or hydroxyurea during pelvic irradiation for locally advanced cervical cancer: a Gynecologic Oncology Group Study. J Clin Oncol (2007) 25:2804-10. doi:10.1200/JCO.2006.09.4532

2. Stehman F, Ali S, Keys H, Muderspach L, Chafe W, Gallup D, et al. Radiation therapy with or without weekly cisplatin for bulky stage $1 \mathrm{~B}$ cervical carcinoma: follow-up of a Gynecologic Oncology Group trial. Am J Obstet Gynecol (2007) 197:503.e1-6. doi:10.1016/j.ajog.2007.08.003

3. Ferlay J, Soerjomataram I, Ervik M, Dikshit R, Eser S, Mathers C, et al. GLOBOCAN 2017 v1.0, Cancer Incidence and Mortality Worldwide. Lyon, France: International Agency for Research on Cancer (2018). Available from: http://globocan.iarc.fr/Default.aspx (Accessed: January 15, 2018).

4. American Cancer Society. Cancer Facts \& Figures 2018. Atlanta: American Cancer Society (2018).

5. Lanciano R, Calkins A, Bundy BN, Parham G, Lucci JA III, Moore DH, et al. Randomized comparison of weekly cisplatin or protracted venous infusion of fluorouracil in combination with pelvic radiation in advanced cervix cancer: a Gynecologic Oncology Group Study. JClin Oncol (2005) 23:8289-95. doi:10.1200/JCO.2004.00.0497

6. Rotman M, Sedlis A, Piedmonte M, Bundy B, Lentz S, Muderspach L, et al. A phase III randomized trial of postoperative pelvic irradiation in stage IB cervical carcinoma with poor prognostic features: follow-up of a Gynecologic Oncology Group Study. Int J Radiat Oncol Biol Phys (2006) 65:169-76. doi:10.1016/j.ijrobp.2005.10.019

7. Kunos C, Radivoyevitch T, Kresak A, Dawson D, Jacobberger J, Yang B, et al. Elevated ribonucleotide reductase levels associate with suppressed radiochemotherapy response in human cervical cancers. Int J Gynecol Cancer (2012) 22:1463-9. doi:10.1097/IGC.0b013e318270577f

8. Kunos C, Winter K, Dicker A, Small WJ, Abdul-Karim FW, Dawson D, et al. Ribonucleotide reductase expression in cervical cancer: a radiation therapy oncology group translational science analysis. Int J Gynecol Cancer (2013) 23:615-21. doi:10.1097/IGC.0b013e31828b4eb5

\section{ETHICS STATEMENT}

These trials were carried out in accordance with the recommendations of Case Western Reserve University and University Hospitals of Cleveland (Cleveland, OH, USA). All patients gave written informed consent in accordance with the Declaration of Helsinki. The Institutional Review Board of Case Western Reserve University and University Hospitals of Cleveland (Cleveland, $\mathrm{OH}, \mathrm{USA}$ ) approved both trial protocols.

\section{AUTHOR CONTRIBUTIONS}

CK and SI contributed to the collection and review of trial data, its analysis and authentication, and the writing and approval of this manuscript.

\section{FUNDING}

CK and SI would like to acknowledge the Cancer Therapy Evaluation Program (CTEP), Division of Cancer Treatment and Diagnosis (DCTD), and National Cancer Institute for supporting this work. The authors would like to thank its contractors for their hard work and efforts to support these two clinical trials over the entire investigational period. Finally, the authors would like to thank the patients and their family members for being involved in these clinical trials.

9. Hakansson P, Hofer A, Thelander L. Regulation of mammalian ribonucleotide reduction and dNTP pools after DNA damage and in resting cells. J Biol Chem (2006) 281:7834-41. doi:10.1074/jbc.M512894200

10. Fairman J, Wijerathna S, Ahmad M, Xu H, Nakano R, Jha S, et al. Structural basis for allosteric regulation of human ribonucleotide reductase by nucleotide-induced oligomerization. Nat Struct Mol Biol (2011) 18:316-22. doi:10.1038/nsmb.2007

11. Kunos C, Radivoyevitch T. Molecular strategies of deoxynucleotide triphosphate supply inhibition used in the treatment of gynecologic malignancies. Gynecol Obstet (Sunnyvale) (2011) (S4):001. doi:10.4172/2161-0932.S4-001

12. Wang J, Lohman G, Stubbe J. Mechanism of inactivation of human ribonucleotide reductase with p53R2 by gemcitabine 5'-diphosphate. Biochemistry (2009) 48:11612-21. doi:10.1021/bi901588z

13. Reece S, Hodgkiss J, Stubbe J, Nocera D. Proton-coupled electron transfer: the mechanistic underpinning for radical transport and catalysis in biology. Philos Trans R Soc Lond B Biol Sci (2006) 361:1351-64. doi:10.1098/rstb.2006.1874

14. Nyholm S, Thelander L, Graslund A. Reduction and loss of the iron center in the reaction of the small subunit of mouse ribonucleotide reductase with hydroxyurea. Biochemistry (1993) 32:11569-74. doi:10.1021/bi00094a013

15. Popovic-Bijelic A, Kowol C, Lind M, Luo J, Himo F, Enyedy E, et al. Ribonucleotide reductase inhibition by metal complexes of triapine (3-aminopyridine-2-carboxaldehyde thiosemicarbazone): a combined experimental and theoretical study. J Inorg Biochem (2011) 105:1422-31. doi:10.1016/j.jinorgbio.2011.07.003

16. Kolberg M, Strand KR, Graff P, Andersson KK. Structure, function, and mechanism of ribonucleotide reductases. Biochim Biophys Acta (2004) 1699:1-34. doi:10.1016/S1570-9639(04)00054-8

17. Eriksson S, Graslund A, Skog S, Thelander L. Cell cycle-dependent regulation of mammalian ribonucleotide reductase. The $\mathrm{S}$ phase-correlated increase in subunit M2 is regulated by de novo protein synthesis. J Biol Chem (1984) 259:11695-700.

18. Chabes A, Thelander L. Controlled protein degradation regulates ribonucleotide reductase activity in proliferating mammalian cells during the normal cell cycle and in response to DNA damage and replication blocks. J Biol Chem (2000) 275:17747-53. doi:10.1074/jbc.M000799200 
19. Tanaka H, Arakawa H, Yamaguchi T, Shiraishi K, Fukuda S, Matsui K, et al. A ribonucleotide reductase gene involved in a p53-dependent cell-cycle checkpoint for DNA damage. Nature (2000) 404:42-9. doi:10.1038/35003506

20. Kunos C, Ferris G, Pyatka N, Pink J, Radivoyevitch T. Deoxynucleoside salvage facilitates DNA repair during ribonucleotide reductase blockade in human cervical cancers. Radiat Res (2011) 176:425-33. doi:10.1667/RR2556.1

21. Kunos C, Chiu S, Pink J, Kinsella T. Modulating radiation resistance by inhibiting ribonucleotide reductase in cancers with virally or mutationally silenced p53 protein. Radiat Res (2009) 172:666-76. doi:10.1667/RR1858.1

22. Kunos C, Radivoyevitch T, Pink J, Chiu S, Stefan T, Jaccobberger J, et al. Ribonucleotide reductase inhibition enhances chemoradiosensitivity of human cervical cancers. Radiat Res (2010) 174:574-81. doi:10.1667/RR2273.1

23. Feun L, Modiano M, Lee K, Mao J, Marini A, Savaraj N, et al. Phase I and pharmacokinetic study of 3-aminopyridine-2-carboxaldehyde thiosemicarbazone (3-AP) using a single intravenous dose schedule. Cancer Chemother Pharmacol (2002) 50:223-9. doi:10.1007/s00280-002-0480-0

24. Murren J, Modiano M, Clairmont C, Lambert P, Savaraj N, Doyle T, et al. Phase I and pharmacokinetic study of triapine, a potent ribonucleotide reductase inhibitor, administered daily for five days in patients with advanced solid tumors. Clin Cancer Res (2003) 9:4092-100.

25. Wadler S, Makower D, Clairmont C, Lambert P, Fehn K, Sznol M. Phase I and pharmacokinetic study of the ribonucleotide reductase inhibitor, 3-aminopyridine-2-carboxaldehyde thiosemicarbazone, administered by 96-hour intravenous continuous infusion. J Clin Oncol (2004) 22:1553-63. doi:10.1200/JCO.2004.07.158

26. Kunos CA, Chu E, Beumer JH, Sznol M, Ivy SP. Phase I trial of daily triapine in combination with cisplatin chemotherapy for advanced-stage malignancies. Cancer Chemother Pharmacol (2017) 79:201-7. doi:10.1007/ s00280-016-3200-x

27. Kunos CA, Chu E, Makower D, Kaubisch A, Sznol M, Ivy SP. Phase I trial of triapine-cisplatin-paclitaxel chemotherapy for advanced stage or metastatic solid tumor cancers. Front Oncol (2017) 7:62. doi:10.3389/fonc.2017.00062

28. Kuo M-L, Kinsella T. Expression of ribonucleotide reductase after ionizing radiation in human cervical carcinoma cells. Cancer Res (1998) 58:2245-52.

29. Kunos CA, Radivoyevitch T, Abdul-Karim FW, Fanning J, Abulafia O, Bonebrake AJ, et al. Ribonucleotide reductase inhibition restores platinumsensitivity in platinum-resistant ovarian cancer: a Gynecologic Oncology Group Study. J Transl Med (2012) 10:79. doi:10.1186/1479-5876-10-79

30. Kunos C, Colussi V, Pink J, Radivoyevitch T, Oleinick N. Radiosensitization of human cervical cancer cells by inhibiting ribonucleotide reductase: enhanced radiation response at low dose rates. Int J Radiat Oncol Biol Phys (2011) 80:1198-204. doi:10.1016/j.ijrobp.2011.01.034

31. Kunos C, Waggoner S, Von Gruenigen V, Eldermire E, Pink J, Dowlati A, et al. Phase I trial of intravenous 3-aminopyridine-2-carboxaldehyde thiosemicarbazone (3-AP, NSC \#663249) in combination with pelvic radiation therapy and weekly cisplatin chemotherapy for locally advanced cervical cancer. Clin Cancer Res (2010) 16:1298-306. doi:10.1158/1078-0432.CCR-09-2469

32. Kunos C, Radivoyevitch T, Waggoner S, Debernardo R, Zanotti K, Resnick K, et al. Radiochemotherapy plus 3-aminopyridine-2-carboxaldehyde thiosemicarbazone (3-AP, NSC \#663249) in advanced-stage cervical and vaginal cancers. Gynecol Oncol (2013) 130:75-80. doi:10.1016/j.ygyno.2013.04.019

33. Chao J, Synold TW, Morgan RJ Jr, Kunos C, Longmate J, Lenz HJ, et al. A phase I and pharmacokinetic study of oral 3-aminopyridine-2-carboxaldehyde thiosemicarbazone (3-AP, NSC \#663249) in the treatment of advanced-stage solid cancers: a California Cancer Consortium Study. Cancer Chemother Pharmacol (2012) 69:835-43. doi:10.1007/s00280-011-1779-5

34. Shankar L, Hoffman J, Bacharach S, Graham M, Karp J, Lammertsma A, et al. Consensus recommendations for the use of 18F-FDG PET as an indicator of therapeutic response in patients in National Cancer Institute Trials. J Nucl Med (2006) 47:1059-66.
35. Kunos C, Radivoyevitch T, Abdul-Karim F, Faulhaber P. 18F-fluoro-2-deoxyD-glucose positron emission tomography standard uptake value as an indicator of cervical cancer chemoradiation therapeutic response. Int J Gynecol Cancer (2011) 21:1117-23. doi:10.1097/IGC.0b013e31821dc8b5

36. Kunos CA, Radivoyevitch T, Ingalls ST, Hoppel CL. Management of 3-aminopyridine-2-carboxaldehyde thiosemicarbazone-induced methemoglobinemia. Future Oncol (2012) 8:145-50. doi:10.2217/fon.11.147

37. Souhami L, Seymour R, Roman TN, Stanimir GW, Trudeau M, Clark BG, et al. Weekly cisplatin plus external beam radiotherapy and high dose rate brachytherapy in patients with locally advanced carcinoma of the cervix. Int J Radiat Oncol Biol Phys (1993) 27:871-8. doi:10.1016/0360-3016(93) 90462-5

38. Bonomi P, Blessing JA, Stehman FB, Disaia PJ, Walton L, Major FJ. Randomized trial of three cisplatin dose schedules in squamous-cell carcinoma of the cervix: a Gynecologic Oncology Group Study. J Clin Oncol (1985) 3:1079-85. doi:10.1200/JCO.1985.3.8.1079

39. Hreshchyshyn MM, Aron BS, Boronow RC, Franklin EW III, Shingleton HM, Blessing JA. Hydroxyurea or placebo combined with radiation to treat stages IIIB and IV cervical cancer confined to the pelvis. Int J Radiat Oncol Biol Phys (1979) 5:317-22. doi:10.1016/0360-3016(79)91209-4

40. Schwarz JK, Siegel BA, Dehdashti F, Grigsby PW. Metabolic response on post-therapy FDG-PET predicts patterns of failure after radiotherapy for cervical cancer. Int J Radiat Oncol Biol Phys (2012) 83:185-90. doi:10.1016/j. ijrobp.2011.05.053

41. Kidd E, Siegel B, Dehdashti F, Grigsby P. The standardized uptake value for F-18 fluorodeoxyglucose is a sensitive predictive biomarker for cervical cancer treatment response and survival. Cancer (2007) 110:1738-44. doi:10.1002/ cncr. 22974

42. Zhang W, Zhao L, Liu J, Du J, Wang Z, Ruan C, et al. Cisplatin induces platelet apoptosis through the ERK signaling pathway. Thromb Res (2012) 130:81-91. doi:10.1016/j.thromres.2012.02.013

43. Liang BC, Ullyatt E. Increased sensitivity to cis-diamminedichloroplatinum induced apoptosis with mitochondrial DNA depletion. Cell Death Differ (1998) 5:694-701. doi:10.1038/sj.cdd.4400401

44. Rose PG, Bundy BN, Watkins EB, Thigpen JT, Deppe G, Maiman MA, et al. Concurrent cisplatin-based radiotherapy and chemotherapy for locally advanced cervical cancer. N Engl J Med (1999) 340:1144-53. doi:10.1056/ NEJM199904153401502

45. Ratner ES, Zhu YL, Penketh PG, Berenblum J, Whicker ME, Huang PH, et al. Triapine potentiates platinum-based combination therapy by disruption of homologous recombination repair. Br J Cancer (2016) 114:777-86. doi:10.1038/bjc. 2016.54

46. Toledo L, Neelsen KJ, Lukas J. Replication catastrophe: when a checkpoint fails because of exhaustion. Mol Cell (2017) 66:735-49. doi:10.1016/j. molcel.2017.05.001

47. Lin ZP, Belcourt MF, Carbone R, Eaton JS, Penketh PG, Shadel GS, et al. Excess ribonucleotide reductase $\mathrm{R} 2$ subunits coordinate the $\mathrm{S}$ phase checkpoint to facilitate DNA damage repair and recovery from replication stress. Biochem Pharmacol (2007) 73:760-72. doi:10.1016/j.bcp.2006.11.014

Conflict of Interest Statement: CK and SI declare that the research was conducted in the absence of any commercial or financial relationships that could be construed as a potential conflict of interest.

Copyright (C) 2018 Kunos and Ivy. This is an open-access article distributed under the terms of the Creative Commons Attribution License (CC BY). The use, distribution or reproduction in other forums is permitted, provided the original author(s) and the copyright owner are credited and that the original publication in this journal is cited, in accordance with accepted academic practice. No use, distribution or reproduction is permitted which does not comply with these terms. 